\title{
Relationship among Stress, Anxiety-depression, Muscle Tone, and Hand Strength in Patients with Chronic Stroke: Partial Correlation
}

\author{
Myoung-Kwon Kim, PT, PhD • Yu-Won Choe, PT, MS ${ }^{1}$ Seong-Gil Kim, PT, PhD ${ }^{2}$ • Eun-Hong Choi, PT, MS ${ }^{\dagger}$ \\ Department of Physical Therapy, College of Rehabilitation Science, Daegu University \\ 'Department of Physical Therapy, Graduate School of Rehabilitation Science, Daegu University \\ ${ }^{2}$ Department of Physical Therapy, Uiduk University
}

Received: July 8, 2018 / Revised: July 27, 2018 / Accepted: September 14, 2018

(c) 2018 J Korean Soc Phys Med

\section{| Abstract |}

PURPOSE: This study was conducted to identify the relationships among stress response inventory, hospital anxiety and depression, muscle tone and stiffness, and hand strength in chronic stroke patients.

METHODS: A total of 14 chronic stroke patients voluntarily agreed to this experiment and were included in this study. All measurements were performed in one day and in a room without noise. The tests conducted in this study were as follows: muscle tone and stiffness of the upper trapezius hand grip measurement. Subjects were also asked to complete surveys describing the following: stress response inventory and hospital anxiety and depression scale.

RESULTS: There were significant correlations among stress response inventory and hospital anxiety and depression, stress response inventory and hand strength, and

$†$ Corresponding Author : Eun-Hong Choi

silvered1@hanmail.net, http://orcid.org/0000-0002-4585-0733

This is an Open Access article distributed under the terms of the Creative Commons Attribution Non-Commercial License (http://creativecommons.org/licenses/by-nc/3.0) which permits unrestricted non-commercial use, distribution, and reproduction in any medium, provided the original work is properly cited. hospital anxiety and depression and hand strength $(P<.05)$. There were high positive correlations between stress response inventory and hospital anxiety and depression $(\mathrm{r}=.979)$, while there were moderate negative correlations between stress response inventory and hand strength $(\mathrm{r}=-.415)$ and between hospital anxiety and depression and hand strength $(\mathrm{r}=-.420)$. CONCLUSION: The results of the present study indicate that there is a relationship among stress response inventory, hospital anxiety and depression, and hand strength in patients with chronic stroke.

Key Words: Depression, Hand strength, Muscle tone, Stress, Stroke

\section{Introduction}

The stroke incidence rate is increasing as the average life span and aging population increase (Rosenberg and Popelka, 2000). Stroke is a major cause of severe chronic disabilities (Kwon et al., 2016). Stroke rehabilitation methods consist of physical and psychological management (Törnbom et al., 2017). Physical management techniques include increasing functional ability (Madden et al., 2006) and methods of psychological management include reducing depression and stress. 
Many recent studies have focused on both physical function and psychological problems in patients with stroke (Carod-Artal and Egido, 2009; Kneebone and Dunmore, 2000; Laures-Gore and DeFife, 2013) because psychological factors greatly influence physical and functional activity (Geisser et al., 2010). Depression, the most common psychiatric condition after stroke, negatively affects functional outcome, response to rehabilitation, and quality of life (Volz et al., 2018; Villa et al., 2018). Psychological stress is thought to play an important role in musculoskeletal disorders by increasing muscle tension in the absence of physical load (Lundberg et al., 1994). Previous studies have also reported that negative emotions decreased muscle strength, and could have negative effects on physical function (Geisser et al., 2010; Papciak and Feuerstein, 1991; Robinson et al., 1992). In addition, emotional stimulation has been reported to influence synaptic plasticity of the brain and descending tracts from the brain (LaLumiere et al., 2017). Additionally, a previous investigation revealed that psychological stress influenced augmentation of the upper trapezius, which is known to be altered by stress and psychological changes (Marker et al., 2017).

Stroke often results in impairments of the upper extremities, including hand and finger function (Ranganathan, 2017). Because hand function is important to many activities, recovery of hand function and skills is a major rehabilitation goal and health care challenge in stroke patients (Franck et al., 2017).

Many previous studies have reported that physical problems as well as psychological and emotional factors are important to the rehabilitation of stroke patients. These psychological factors are thought to influence the muscle tone and hand strength of stroke patients. However, no studies have investigated the relationships among stress, depression, muscle tone, and hand strength in chronic stroke patients. Therefore, this study was conducted to define those relationships.

\section{Methods}

\section{Participants}

A total of 14 chronic stroke patients who voluntarily agreed to this experiment were included in this study. Prior to the start of the study, all subjects understood its content and signed an informed consent form. This study complied with the ethical standards of the Declaration of Helsinki. Subjects of this study were required to meet the following inclusion criteria. 1) Stress Response Inventory Score $>50$; 2) Hospital Anxiety and Depression Scale $>15$; 3) Chronic stroke patients hospitalized for $>6$ months (Colomer et al., 2016); 4) Mini-Mental State Examination-Korean version (MMSE-K) scores $>26$ (Go and Lee, 2016); 5) No increase or slight increase in muscle tone as defined by a Modified Ashworth Scale (MAS) score $<3$ on the paretic side (Colomer et al., 2016); 6) No musculoskeletal impairment of the upper extremities; and 7) Able to sufficiently participate in conversation. Subjects who met the following criteria were excluded from the study. 1) other neurological conditions in addition to stroke; 2) unstable cardiovascular disease; or 3) other serious diseases (Pang et al., 2007).

\section{Measurement}

In this study, all measurements were performed in one day. Every measurement was taken in a room without noise. The tests conducted in this study were as follows: muscle tone and stiffness measurement of the upper trapezius, hand grip measurement, Stress Response Inventory, and Hospital Anxiety and Depression Scale. Hand grip was measured after muscle tone of the upper trapezius to prevent increased upper trapezius muscle tone due to hand muscle contraction.

\section{1) Muscle tone and stiffness}

Muscle tone of the upper trapezius on the affected side was measured using MyotonPRO (Myoton AS, Tallinn, Estonia). The MyotonPRO device was employed to measure muscle tone or tension (Hz: Natural Oscillation 
Table 1. General Subject Characteristics $(n=14)$

\begin{tabular}{cc}
\hline Variable & Mean \pm SD \\
\hline Age (year) & $61.50 \pm 3.42$ \\
Height (cm) & $164.21 \pm 7.49$ \\
Weight (kg) & $62.29 \pm 9.75$ \\
MMSE & $27.43 \pm 1.20$ \\
Disease period (month) & $21.76 \pm 9.12$ \\
StressRI (score) & $63.50 \pm 4.92$ \\
Dep (score) & $19.93 \pm 2.26$ \\
MyoF (Hz) & $18.73 \pm 2.62$ \\
MyoS (N/m) & $351.07 \pm 78.82$ \\
Hand strength (kg) & $19.68 \pm 7.89$ \\
\hline
\end{tabular}

SD, standard deviation, StressRI : Stress Response Inventory, dep : Hospital Anxiety and Depression Scale, MyoF muscle tone (Natural Oscillation Frequency), MyoS: muscle stiffness (Dynamic Stiffness).

Frequency) and stiffness (N/m: Dynamic Stiffness), and the mean values were analyzed (Park et al., 2017). This device showed high to very high ICC values $\left(.85^{-} .94\right)$ (Pruyn et al., 2016). The measurement procedure involved pressing the device against the skin, after which the skin surface oscillation induced by the MyotonPRO was measured to verify the value of mechanical variability (Park et al., 2017; Bailey et al., 2013). Muscle tone was measured only once in the sitting position. This study used the mean value of three taps, with a tap time of $15 \mathrm{~ms}$. The upper trapezius was measured with subjects seated on a chair. Briefly, subjects leaned back and rested their arms on an armrest during the measurement, and all subjects sat on the same chair. The upper trapezius muscle belly located midway from the acromion to the spinous process of $\mathrm{C} 7$ was palpated and measured (Park et al., 2017; Viir et al., 2006). An experimenter drew a dot and placed the testing end of the MyotonPRO on the skin surface overlying the muscle belly, then recorded the data (Marusiak et al., 2011).

\section{2) Hydraulic Hand Dynamometer}

Hand strength was measured with the Jamar® Hydraulic
Hand Dynamometer (Patterson Medical, Warrenville, IL, USA), which has excellent test-retest reliability ( $\mathrm{ICC}=.97)$ (Mathiowetz, 2002; Savva et al., 2014). For this test, hand strength on the affected side was measured only once in the sitting position. Participants were seated on a standard height chair without armrests and positioned according to the American Society of Hand Therapists' recommendation. For the assessments, subjects were seated with the shoulder adducted and neutrally rotated, elbow flexed at $90^{\circ}$ with the forearm in neutral position, and wrists between $0^{\circ}$ and $30^{\circ}$ of flexion and $0^{\circ}$ and $15^{\circ}$ of ulnar deviation (Fess, 1982; Lam et al., 2016; Shim et al., 2013).

\section{3) Stress Response Inventory}

The Stress Response Inventory developed by Koh et al. (2001) measures reactions to emotional, physical, cognitive, and behavioral stress. The test-retest reliability of the Stress Response Inventory is high, ranging from .69 to .96 . Accordingly, the Stress Response Inventory can be utilized as an effective measure of stress for research in stress-related fields (Koh et al., 2001). This scale consists of total of 39 response items under seven subscales (Tension, Aggression, Somatization, Anger, Depression, Fatigue, Frustration). There are six items under the tension subscale, four under the aggression subscale, three under the somatization subscale, six under the anger subscale, eight under the depression subscale, five under the fatigue subscale, and seven under the frustration subscale. Of the total items, eight were emotional types of responses, 11 were somatic, eight were cognitive, nine were behavioral, and three consisted of a mixture of cognitive and emotional elements. Of the eight cognitive response items, four were under the depression subscale, two were under frustration, one was under tension, and one was under the fatigue subscale (Koh et al., 2001). The Stress Response Inventory is based on a 5-point, Likert-type sclae with the following values: 'Not at all' (0 points), 'Somewhat' (1 point), 'Moderately' (2 points), 'Very much' (3 points), or 
Table 2. Partial Correlations Among Stress, Depression, Muscle Tone, and Grip Strength

\begin{tabular}{|c|c|c|c|c|c|c|}
\hline Control Variable & Variables & & dep (score) & MyoF (Hz) & MyoS (N/m) & Hand strength $(\mathrm{kg})$ \\
\hline \multirow{8}{*}{ Disease period } & \multirow{2}{*}{ StressRI (score) } & correlation & $.979 * *$ & .243 & .241 & $-.415^{*}$ \\
\hline & & $\mathrm{P}$ & .000 & .221 & .225 & .032 \\
\hline & \multirow{2}{*}{ dep (score) } & correlation & & .214 & .226 & $-.42 *$ \\
\hline & & $\mathrm{P}$ & & .284 & .257 & .029 \\
\hline & \multirow{2}{*}{ MyoF (Hz) } & correlation & & & $.953 * *$ & .252 \\
\hline & & $\mathrm{P}$ & & & .000 & .205 \\
\hline & \multirow{2}{*}{$\operatorname{MyoS}(\mathrm{N} / \mathrm{m})$} & correlation & & & & .222 \\
\hline & & $\mathrm{P}$ & & & & .267 \\
\hline
\end{tabular}

* $P<.05,{ }^{* *} P<.01$, StressRI: Stress Response Inventory, dep: Hospital Anxiety and Depression Scale, MyoF muscle tone (Natural Oscillation Frequency), MyoS: muscle stiffness (Dynamic Stiffness).

'Absolutely' (4 points) (Koh et al., 2001). The highest possible score was 156 , and higher scores indicated higher stress. The test-retest reliability of the seven subscale scores and the total score was high, ranging between .69 and .96 . (Koh et al., 2001). Internal consistency was computed, and Cronbach's alpha for the seven subscales ranged between $.76-.91$ and .97 for the total score (Koh et al., 2001).

\section{4) Hospital Anxiety and Depression Scale (HADS)}

The Hospital Anxiety and Depression Scale (HADS) developed by Zigmond and Snaith (1983) is an effective tool that evaluates patient anxiety, depression, and emotional state. The reliability and validity of HADS has been confirmed by many researchers and is standardized in many countries. The HADS internal consistencies (Cronbach alpha) are acceptable at $.80-.93$ for anxiety and .81-.9 for depression (Herrmann, 1997; Lisspers et al., 1997; Malasi et al., 1991). This study used the Korean-version of the HADS. The reliability of the Korean-version of the HADS (Cronbach's alpha) was .89 (anxiety) and .86 (depression). The Hospital Anxiety and Depression Scale consists of 14 items, seven evaluating anxiety (HADS-A) and seven evaluating depression (HADS-D). Each of the items receives a score that varies from $0-3$, for a total of up to 21 points for each subscale.
The highest possible score is 42 , and a higher score indicates higher anxiety and depression.

\section{Statistical analysis}

SPSS version 22.0 (IBM Corporation, Armonk, NY, USA) was used for statistical analysis. Descriptive statistics was used to measure general characteristics of the subject. A partial correlation coefficient was used to determine the correlation among stress, depression, muscle tone, and hand strength. To exclude confounding factors influencing other variables, disease period was used as the controlling variable. The statistical significance was set at $\alpha=.05$.

\section{Results}

There were significant correlations among stress and depression, stress and hand strength, and depression and hand strength $(P<.05)$. In addition, there were high positive correlations between stress and depression ( $\mathrm{r}=979)$. Conversely, there were low negative correlations between Stress RI and hand strength $(r=-.415)$ and between depression and hand strength $(\mathrm{r}=-.42)$ (Table 2).

In general, if the size of a correlation is less than .5 , there is no clinical significance, but in a previous study, a low correlation was found between .3 and .5 (Mukaka, 2012). 


\section{Discussion}

This study was conducted to analyze the relationship among stress RI, depression, muscle tone and hand strength in chronic stroke patients. The results showed a strong positive correlation between stress and depression, and low negative correlations between stress and hand strength, and depression and hand strength.

It has been reported that stroke patients are often stressed during the rehabilitation process, which leads to various psychological problems such as depression, pain, and anxiety due to the negative effects on physical activities, all of which make the rehabilitation process difficult.

In a previous study, 45 chronic stroke patients were divided into two groups according to the presence or absence of stress. Results showed that the quadriceps muscle strength, balance and walking ability (walking and stair climbing speed) were significantly decreased in the group with stress (Jaruwan et al., 2014). The results of that study support the low negative correlation between hand strength and stress in the current study. In another study comparing depression and muscle strength, 23 subjects with ischemic stroke were divided into two groups, and depression was compared after 12 weeks of strength training in the experimental group. That study showed that depression was significantly reduced in the group that exercised, resulting in a negative correlation between muscle strength and depression (Felipe et al., 2014). Moreover, Marker et al. (2017) reported that disinhibition of stress contributes to an increase in muscle activity. As in previous studies, the decrease of stress and depression in the rehabilitation of patients seems to be closely related to the improvement of the patients' muscle strength.

In addition, a study evaluating the effects of music and movement therapy on the physical and psychological functions of stroke patients in hospitals showed that psychological functional status, shoulder flexion and elbow flexion were improved in a group treated with music and movement (Jun et al., 2012). Taken together, these results from previous studies support the low negative correlations observed among stress and depression and hand strength in the present study. Therefore, it is important to reduce stress and depression to improve rehabilitation therapy.

\section{Conclusion}

The results of the present study indicate that there is a relationship among stress, depression, and hand strength in patients with chronic stroke. The low correlations between stress and hand strength and between depression and hand strength suggest that the emotional status of patients with chronic stroke should be considered before treatment to promote more effective muscle recovery.

\section{References}

Bailey L, Samuel D, Warner M, et al. Parameters representing muscle tone, elasticity and stiffness of biceps brachii in healthy older males: symmetry and within-session reliability using the MyotonPRO. J Neurol Disord. 2013;1(1):1-7.

Carod-Artal FJ, Egido JA. Quality of life after stroke: the importance of a good recovery. Cerebrovasc Dis 2009;27(1): 204-14.

Colomer C, Llorens R, Noé E, et al. Effect of a mixed reality-based intervention on arm, hand, and finger function on chronic stroke. J Neuroeng Rehabil. 2016; 13(1):45.

Felipe JA, Dihogo GM, Ricardo JO, et al. Victor MR. Relationship between depression and strength training in survivors of the ischemic stroke. Journal of human kinetics. 2014;43:7-15.

Fess EE. The effects of Jaymar dynamometer handle position and test protocol on normal grip strength. Journal of Hand Surgery. 1982;7(3):308-9.

Franck JA, Smeets RJEM, Seelen HAM. Changes in arm-hand 
function and arm-hand skill performance in patients after stroke during and after rehabilitation. PloS one. 2017;12(6):1-18.

Geisser ME, Robinson ME, Miller QL, et al. Psychosocial factors and functional capacity evaluation among persons with chronic pain. Journal of occupational rehabilitation. 2010;13(4):259-76.

Go EJ, Lee SH. Effect of sensorimotor stimulation on chronic stroke patients' upper extremity function: a preliminary study. Journal of physical therapy science. 2016; 28(12):3350-3.

Herrmann C. International experiences with the Hospital Anxiety and Depression Scale-a review of validation data and clinical results. Journal of psychosomatic research. 1997;42(1):17-41.

Jaruwan P, Chitima J, Sunee B, et al. Walking and stair climbing abilities in individuals after chronic stroke with and without mental health problem. J Med Assoc Thai. 2014;97(7):10-5.

Jun EM, Roh YH, Kim MJ. The effect of music-movement therapy on physical and psychological states of stroke patients. Journal of Clinical Nursing. 2012;22:22-31.

Kneebone II, Dunmore E. Psychological management of post-stroke depression. British Journal of Clinical Psychology. 2000;39:53-65.

Koh KB, Park JK, Kim CH, et al. Development of the stress response inventory and its application in clinical practice. Psychosomatic medicine. 2001;63(4):668-78.

Kwon SY, Hong SE, Kim EJ, et al. Monitoring of functioning status in subjects with chronic stroke in South Korea using WHODAS II. Annals of rehabilitation medicine. 2016;40(1):111-9.

LaLumiere RT, McGaugh JL, McIntyre CK. Emotional modulation of learning and memory: Pharmacological implications. Pharmacological Reviews. 2017;69(3): 236-55.

Lam NW, Goh HT, Kamaruzzaman SB, et al. Normative data for hand grip strength and key pinch strength, stratified by age and gender for a multiethnic Asian population. Singapore medical journal. 2016;57(10):578-84.

Laures-Gore JS, DeFife LC. Perceived stress and depression in left and right hemisphere post-stroke patients. Neuropsychological rehabilitation. 2013;23(6):783-97.

Lisspers J, Nygren A, Söderman E. Hospital Anxiety and Depression Scale (HAD): some psychometric data for a Swedish sample. Acta Psychiatrica Scandinavica. 1997;96(4):281-6.

Lundberg U, Kadefors R, Melin B. Psychophysiological stress and EMG activity of the trapezius muscle. International Journal of Behavioral Medicine. 1994; 1(4):354-70

Madden S, Hopman WM, Bagg S, et al. Functional status and health-related quality of life during inpatient stroke rehabilitation. American journal of physical medicine and rehabilitation. 2006;85(10):831-8.

Malasi TH, Mirza IA, El-Islam MF. Validation of the hospital anxiety and depression scale in Arab patients. Acta psychiatrica scandinavica. 1991;84(4):323-6.

Marker RJ, Campeau S, Maluf KS. Psychosocial stress alters the strength of reticulospinal input to the human upper trapezius. Journal of neurophysiology. 2017;117(1): 457-66.

Marusiak J, Jaskólska A, Budrewicz S, et al. Increased muscle belly and tendon stiffness in patients with Parkinson's disease, as measured by myotonometry. Movement Disorders. 2011;26(11):2119-22.

Mathiowetz V. Comparison of Rolyan and Jamar dynamometers for measuring grip strength. Occupational therapy international. 2002;9(3):201-9.

Mukaka MM. A guide to appropriate use of correlation coefficient in medical research. Malawi medical journal. 2012;24(3):69-71.

Pang MY, Eng JJ, Miller WC. Determinants of satisfaction with community reintegration in older adults with chronic stroke: role of balance self-efficacy. Physical therapy. 2007;87(3):282-91. 
Papciak AS, Feuerstein M. Psychological factors affecting isokinetic trunk strength testing in patients with work-related chronic low back pain. Journal of occupational rehabilitation. 1991;1(2):95-104.

Park SK, Yang DJ, Kim JH, et al. Analysis of mechanical properties of cervical muscles in patients with cervicogenic headache. Journal of physical therapy science. 2017;29(2):332-5.

Pruyn EC, Watsford ML, Murphy AJ. Validity and reliability of three methods of stiffness assessment. Journal of Sport and Health Science. 2016;5(4):476-83.

Ranganathan R. Reorganization of finger coordination patterns through motor exploration in individuals after stroke. Journal of neuroengineering and rehabilitation. 2017; 14(1):90.

Robinson ME, O'Connor PD, MacMillan M, et al. Physical and psychosocial correlates of test-retest isometric torque variability in patients with chronic low back pain. Journal of occupational rehabilitation. 1992; 2(1):11-8.

Rosenberg CH, Popelka GM. Post-stroke rehabilitation: A review of the guidelines for patient management. Geriatrics. 2000;55(9):75-81.

Savva C, Giakas G, Efstathiou M, et al. Test-retest reliability of handgrip strength measurement using a hydraulic hand dynamometer in patients with cervical radiculopathy. Journal of manipulative and physiological therapeutics. 2014;37(3):206-10.

Shim JH, Roh SY, Kim JS, et al. Normative measurements of grip and pinch strengths of 21st century korean population. Archives of plastic surgery. 2013; 40(1):52-6.

Törnbom K, Persson HC, Lundälv J, et al. The impact of physical function on participation in the first year post-stroke. Acta Neurologica Scandinavica. 2017; 135(6):649-55.

Viir R, Laiho K, Kramarenko J, et al. Repeatability of trapezius muscle tone assessment by a myometric method. Journal of Mechanics in Medicine and Biology. 2006;6(2):215-28.

Villa RF, Ferrari F, Moretti A. Post-Stroke Depression: Mechanisms and Pharmacological Treatment. Pharmacology and therapeutics. 2018;184:131-44.

Volz M, Voelkle MC, Werheid K. General self-efficacy as a driving factor of post-stroke depression: A longitudinal study. Neuropsychological rehabilitation. 2018. https://doi.org/10.1080/09602011.2017.1418392.

Zigmond AS, Snaith RP. The hospital anxiety and depression scale. Acta psychiatrica scandinavica. 1983;67(6): 361-70. 